\title{
ENTRE MULHERES: O ENSINO DOMÉSTICO E A PROFISSÃO
}

Álvaro Ribeiro

Instituto de Educação, Universidade do Minho

\section{Resumo}

A partir de uma pesquisa qualitativa realizada em Portugal sobre famílias que praticam ensino doméstico, o autor dá a conhecer as diferentes abordagens que as mães tecem como gestoras dos planos dos percursos familiares. Tendo o lar como micro-organizações, entre a burocracia racional e os modelos anárquicos, dos tipos ideais de famílias estudados, o autor defende que as mães assumem uma carreira sem fronteiras por tenderem a abandonar a ideia de carreira profissional delimitada por fronteiras organizacionais. Durante o período de escolaridade obrigatória dos seus filhos, estas mulheres tendem a fazer a autogestão do seu autoemprego como estratégia de conseguirem um maior equilíbrio entre o ensino doméstico dos seus filhos e o trabalho.

Palavras-chave: ensino doméstico, mulheres, profissão, gestora familiar.

\section{Abstract}

\section{Between women: homeschooling and profession}

Based on a qualitative research held in Portugal on families who practice homeschooling, the author sets forth the different approaches that mothers weave as managers of familiar plans. Taking homes as micro-organizations, between the rational bureaucracy and anarchic models, the author argues that mothers take a borderless career and tend to abandon the idea of career bounded by organizational boundaries. During the period of compulsory schooling of their children, these women tend to do self-management of their self-employment as a strategy to achieve a better balance between the homeschooling of their children and work.

Keywords: homeschooling, women, profession, family manager.

\section{Resumen}

\section{Entre las mujeres: educación en casa y la profesión}

Sobre la base de un estudio cualitativo llevado a cabo en Portugal en las familias que hacen la educación en casa, el autor da a conocer los diferentes enfoques que se tejen las madres como managers de los planes de rutas familiares. Tomando la casa como microorganizaciones, entre la burocracia racional y modelos anárquicos, de los tipos ideales de familias estudiadas, el autor sostiene que las madres tienen una carrera sin fronteras, tendiendo a abandonar la idea de carrera limitada por las fronteras organizacionales. Durante el periodo de la educación obligatoria de los hijos, estas mujeres abrazan la autogestión de su trabajo por cuenta propia como una estrategia para lograr un mejor equilibrio entre la educación en casa a sus hijos y el trabajo.

Palabras-clave: la educación en casa, mujeres, profesión, gestión de la familia. 


\section{No caminho de novas abordagens ao trabalho doméstico e à profissão}

Na decorrência da implementação das políticas da Nova Direita, há na sociedade portuguesa uma outra visão de cultura profissional feminina que algumas mulheres têm estado a construir e que relacionam educação, ensino doméstico, formação superior, trabalho e carreira profissional. Referimo-nos a mães que, a despeito das suas habilitações académicas e experiências profissionais, têm vindo a dedicar tempo inteiro à educação doméstica dos seus filhos durante, e se possível, todo o período de escolaridade obrigatória.

Estas mães assumem a gestão da esfera familiar de forma total e radical porque lhes é vital. Se anteriormente fizeram parte da feminização da população ativa, isto é, da crescente participação das mulheres no mundo das profissões e, em particular, naquelas altamente qualificadas, as alterações nos seus padrões de carreira por influência de fatores contextuais religiosos, filosóficos e microculturais familiares, denotam a construção de outros reconhecimentos materiais e simbólicos atribuídos à profissão, assim como às relações de poder entre os profissionais de ambos os sexos que constituem a família em sentido estrito.

Neste domínio, à luz de Michael Arthur (1994), temos verificado que estas mães assumem uma carreira sem fronteiras quando abandonam definitivamente a ideia de carreira profissional delimitada por fronteiras organizacionais, abraçando a autogestão do seu autoemprego como estratégia de conseguirem um maior equilíbrio entre o ensino doméstico dos seus filhos e trabalho (quanto baste), sobretudo à custa das novas tecnologias de informação e comunicação.

Ainda que longe dos milhões de alunos/as que o praticam nos Estados Unidos da América (Stevens, 2001) e de muitos milhares que o fazem noutros países (Apple, 2012; Ribeiro, 2015), segundo os dados que possuímos, nos últimos anos temos vindo a assistir ao aumento do número de alunos/as que realizam ensino doméstico em Portugal (Ribeiro, 2015). Segundo o trabalho jornalístico de Sandra Freitas (2015: 6), ficamos a saber que os alunos/as que praticam ensino doméstico «em dois anos letivos passaram de 76 para 338». Do quadro n. 1, sem termos conseguido informação sobre o número de alunos/as com matrícula em ensino doméstico no ano letivo 2011/2012, nota-se entre um claro crescimento desde o ano letivo 2006/2007. Talvez por défices da nossa informação verifica-se um decréscimo no ano letivo 2012/2013 face ao registo anterior. No ano letivo 2013/2014 há o registo de 338 com matrícula em ensino doméstico, o que representa um aumento maior do que a quadruplicação do registo anterior.

\section{Quadro 1}

Comportamento numérico de alunos/as com matrícula em ensino doméstico em Portugal, segundo o ano letivo

\begin{tabular}{cccccccc}
\hline 2006-2007 & $2007-2008$ & 2008-2009 & 2009-2010 & 2011-2011 & 2011-2012 & 2012-2013 & 2013-2014 \\
\hline 6 & 44 & 67 & 82 & 97 & Sem informação & 76 & 338 \\
\hline
\end{tabular}

Fonte: Elaboração do autor. 
Em Portugal, os últimos anos têm sido profícuos em atividades sociais em prol do ensino doméstico. No gráfico 1, salientamos a frequência da cobertura televisiva, pois são trabalhos de jornalistas que tendo os seus «óculos particulares através dos quais vêm certas coisas e não outras; e vêm de uma certa maneira as coisas que veem», operam um impacto na opinião pública em jeito de «dramatização, no duplo sentido da palavra», colocando «em imagens, um acontecimento e [exagerando] a sua importância, a sua gravidade e o seu caráter dramático, trágico» (Bourdieu, 2005: 12), aqui em desfavor da Escola. Entendido isto, na linha deste autor, «os perigos políticos que são inerentes ao uso habitual da televisão ligam-se ao facto de a imagem ter a particularidade de poder produzir o efeito real, de poder fazer ver e crer no que faz ver», com o potencial próprio de mobilização de ideias, representações e grupos «de molde a desencadear sentimentos fortes, muitas vezes negativos», (Bourdieu, 2005: 14), neste caso sobre a Escola como refere Michael Apple (2001).

\section{Gráfico 1}

Friso cronológico de eventos mediáticos do ensino doméstico

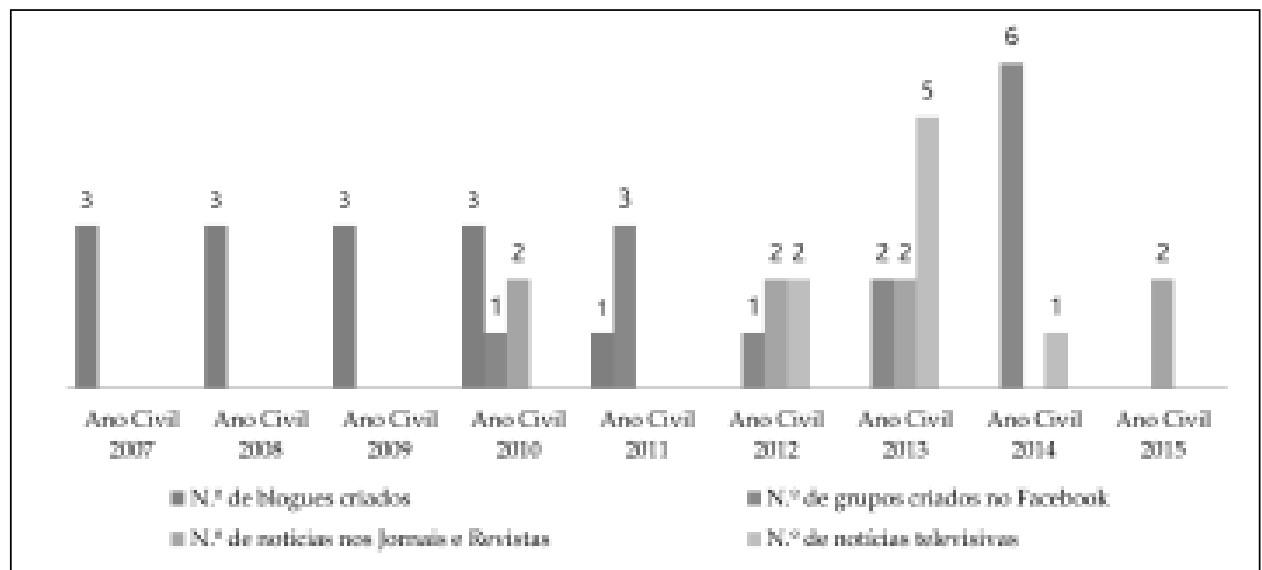

Fonte: Elaboração do autor.

No sentido de examinarmos este novo movimento social, de acordo com Mitchel Stevens (2001), que provê contexto para a renovação do estatuto e papel laboral e profissional da mãe, é necessário «analisar criticamente o tipo de trabalho que é requerido no ensino doméstico, quem está envolvido e como é interpretado pelos atores que o desempenham» (Apple, 2012: 52). Como muito deste trabalho está escondido socialmente, neste texto pretendemos dar a conhecer as dinâmicas posicionais das mães e das famílias que realizam este tipo de ensino sobre a produção de soluções de mercado e de trabalho que encontram para satisfazerem os seus interesses e necessidades ideológicas. Neste contexto, o facto 
de $97 \%$ das mães inquiridas ( $n=78$ ), que administram o ensino doméstico em Portugal terem declarado que já trabalharam, é um dado a ter em conta para aferir-se a tendência do ensino doméstico contrariar a feminização da população ativa e saber como estas famílias se comportarão em função dos fluxos de emprego/ /desemprego (Ribeiro, 2015).

Uma vez que o ensino doméstico é uma das maiores tendências da privatização da educação, e que não tem mostrado sinais de desvanecimento, (Bendell, 1994; Kunzman, 2009), construímos este texto em três momentos. Depois de enquadrarmos o ensino doméstico na senda das crises simultâneas do Estadoprovidência, do trabalho e do sujeito como uma evolução moral intrínseca ao triunfo da lógica mercantil, avançamos para considerar este novo movimento social nas lógicas do empreendedorismo maternal e suas relações com a profissão das mães e educação.

\section{Do desenho da investigação}

Este texto é construído a partir de um modelo teórico que analisa o ensino doméstico num contínuo entre dois tipos ideais de famílias: as que são conservadoras crentes cristãs protestantes e as famílias conservadoras progressistas-libertárias. Este contínuo é cruzado entre a formalidade e a informalidade das práticas quotidianas familiares.

Dentro do espírito epistemológico interpretativo, típico das metodologias qualitativas, o objetivo não é representar o mundo do ensino doméstico em Portugal, de o inferir, mas antes potenciar o heurístico dos submundos a partir dos vários casos.

O conhecimento empírico que sustenta este texto decorre de uma abordagem qualitativa em que, a partir do método de estudo de caso - variante multicasos, consideram-se informações provenientes da observação das práticas familiares (quadro 2), entrevistas realizadas a 24 famílias (quadro 3), 5 grupos focais (quadro 4). Dadas as dificuldades de aceder a mais famílias, seja pela distância geográfica do investigador ou pela desconfiança em nos receber, concebemos um questionário eletrónico que foi enviado a 118 famílias, tendo sido respondidos e devolvidos $66 \%(n=78)$. Analisamos blogues do ensino doméstico em Portugal num total de 4.648 mensagens e 2.575 comentários, grupos no facebook num total de 3.876 mensagens e 3.013 comentários. Para além das notas de campo, analisamos também trocas de correio eletrónico, atos legislativos, ideários e projetos educativos das organizações de apoio, diários e relatórios das famílias, testemunhos, artigos de revistas públicas e guias práticos de ensino doméstico em Portugal. 
Quadro 2

Duração das observações, por famílias

\begin{tabular}{cccccc}
\hline F1 & F2 & F3 & F4 & F5 & F6 \\
\hline Porto & Évora & Santarém & Coimbra & Aveiro \\
\hline \multicolumn{7}{c}{30 Horas } \\
\hline \multicolumn{7}{c}{}
\end{tabular}

Quadro 3

Caracterização das famílias entrevistadas

\begin{tabular}{cccc}
\hline Distrito & N. ${ }^{0}$ de famílias & N..$^{0}$ de pessoas entrevistadas & Duração da entrevista \\
\hline Braga & 1 & & \\
\hline Porto & 3 & & \\
\hline Aveiro & & 18 Mães & \\
Coimbra & & 8 Pais & \\
Castelo branco & 5 & 7 Filhos/as & \\
Leiria & & & \\
Santarém & & & \\
\hline Lisboa & 12 & \\
\hline Évora & & \\
Sintra & 3 & \\
Faro & & \\
\hline
\end{tabular}

Quadro 4

Caracterização dos focus groups

\begin{tabular}{lcccccc}
\hline Distrito & Braga & Coimbra & Lisboa - I & Lisboa - II & Setúbal & Totais \\
\hline $\begin{array}{l}\text { N. }{ }^{-0} \text { participantes } \\
\text { Duração }\end{array}$ & $5(4 \mathrm{M}, 1 \mathrm{~F})$ & $12(3 \mathrm{M}, 9 \mathrm{~F})$ & $8(1 \mathrm{M}, 7 \mathrm{~F})$ & $3(2 \mathrm{M}, 1 \mathrm{~F})$ & $12(2 \mathrm{M}, 10 \mathrm{~F})$ & $40(12 \mathrm{M}, 28 \mathrm{~F})$ \\
& & & & & & 10 horas \\
\hline
\end{tabular}

Fonte: Elaboração do autor.

O facto do sujeito em causa ser pouco acessível e difícil de encontrar fez com que começássemos por selecionar um indivíduo de interesse, que depois recomendou individualmente outros indivíduos frequentadores, que por sua vez recomendaram outros, tornando possível desta forma o aumento da dimensão da amostra geometricamente. Neste tipo de propagação geométrica, snowball, o único critério de relevância cultural para a seleção dos praticantes foi praticar ensino doméstico em Portugal continental.

A análise dos dados recolhidos foi efetuada segundo a análise de conteúdo e a semântica quantitativa. Nesta relação procuramos mover-nos entre a criação e atribuição de significados às coisas e às pessoas nas interações sociais, e as verificações objetivas, amparadas em frequências estatísticas. A análise de conteúdo aqui usada foi no sentido em que normalmente não permite generalizações (Landis 
e Koch, 1977). Levando em conta que os resultados mais credíveis são aqueles que não necessitam de ser satinizados por procedimentos estatísticos complicados (Maruyama e Deno, 1992) e que a sobrevalorização da técnica em nome da boa ciência ultrapassa as próprias necessidades da teoria (Estêvão, 1998), recorremos sobretudo a procedimentos qualitativos e a cálculos estatísticos simples. Não usamos técnicas estatísticas mais convencionais como a análise de regressão dado que está demasiado de acordo com uma sociologia das variáveis que, ao hipervalorizar as relações específicas entre a dependência (variável explicada) e a independência (variável explicativa), o recurso a esta medida de análise estatística tende, no entender de Bourdieu (1984: 103) «a dissimular o sistema completo de relações que constitui o verdadeiro princípio da força e de forma específicos aos efeitos registados numa tal e tal correlação particular». Tivemos presente a triangulação, o cotejar, o destacar do significado dos casos raros ou excecionais. Para extrair conclusões, salientamos temas, buscamos plausibilidade de acordo com o quadro teórico, destacamos variáveis, incluímos o particular no geral. Não nos resumimos a captar representações e identidades sociais de género a partir das práticas domésticas, mas a tentar abarcar o enquadramento (setting) influenciador e penetrador das significações partilhadas (shared meanings) nas dinâmicas laborais domésticas e a partir delas. Esta investigação decorreu entre os anos 2012 e 2015.

\section{Das crises do Estado-providência, trabalho e sujeito à refundação do estatuto e do papel da mãe doméstica}

O ensino doméstico confronta o estatuto e papel laboral das mães que o asseguram. Usamos este termo por estar formalmente categorizado na literatura. Porém, somos da opinião de que o conceito education at home poderá abranger mais e melhor as diferentes realidades familiares. A partir da pena de quem legisla para quem o ensino doméstico é aquele que é lecionado no domicílio de aluno ou aluna por um familiar ou por pessoa que com ele ou ela habite, a análise das práticas que temos observado direciona-nos para um ato educativo que subjaz e permeia uma alternativa ao ato escolar que significa mais do que a alternativa organizacional, curricular, avaliativa e administrativa face à oferta escolarizante convencional (Ribeiro, 2010). É mais do que o ato escolar em casa. É o aumento da amplitude e aprofundamento de um ato educativo familiar que é mais do que a perspetiva do schooling. Sendo um conceito ainda à procura de sedimentação, evoca um forte desejo das famílias de ressemantizar o ser humano na esteira da ideologia e pedagogia familiares e em tudo mais que estas famílias entenderem.

Desenvolvendo-se num enquadramento assente em «estruturas objetivas independentes da consciência e da vontade dos agentes que são capazes de orientar e limitar as suas práticas e representações» (Bourdieu, 1990: 149), da 
transição aqui patente do government para governance, o ensino doméstico tem sido favorecido por um tipo de Estado que tem acentuado a sua redução à garantia da ordem pública, regulação do mercado (menos Estado), soberania nacional e legalidade dos contratos do funcionamento do mercado (Afonso, 1998).

Esta narrativa está bem alicerçada no pensamento social das famílias que praticam ensino doméstico em Portugal uma vez que, segundo o seu posicionamento entre o que valorizam e rejeitam, nota-se uma relação a favor da public choice, enterprising e performance (Ribeiro, 2015). Só que da importação da iniciativa empresarial, a sociedade funciona cada vez mais como um «agente de uma exclusão específica que transforma a experiência dos sujeitos» abrindo uma crise de sentido e de legitimidade institucional (Dubet, 2003: 43).

A aplicação do económico à política e ao conceito de indivíduo como ator racional tem deslocado o debate das mudanças sociais para arenas externas às instituições de laço social que incluem famílias que praticam ensino doméstico e o tecido empresarial associado aos think-tanks e grupos de pressão patrocinados por organizações internacionais. Ora, daqui há efeitos sociais de naturalização, dessocialização e des-historização que as elites capitalistas e burguesas estatais têm construído ao substituírem o conceito de cidadão pelo de consumidor, estipulando como critério de inclusão a solvência e já não o direito (Santos, 2001).

Se há mães que concebem o ensino doméstico dos seus filhos e filhas como um direito pelas alusões que fazem ao facto de que «aos pais pertence a prioridade do direito de escolher o género de educação a dar aos filhos» conforme o número 3 do artigo 26. da Declaração Universal dos Direitos Humanos ${ }^{1}$, é também verdade que a acentuação dos bens e serviços privados, pela perda da sua natureza pública, traz em si, inevitavelmente, que as famílias sem recursos financeiros serão as insolventes para esta prática.

Sendo a temática desta revista género, profissões e carreiras, destacamos que o afastamento progressivo do papel do Estado na sociedade ao nível de uma atitude protecionista tem favorecido a sua reconcetualização instrumental, seletiva, excludente e desagremiadora, cujos fatores e processos económicos, políticos e culturais traduzem a existência de um mercado de trabalho de «incertezas em relação aos direitos sociais conseguidos na esfera nacional» (Afonso, 2001: 22-23). Por isso, torna-se necessário inscrever na agenda política processos de «reconfiguração e ressignificação das cidadanias» que resultem, entre outros factores, «do confronto com manifestações cada vez mais heterogéneas e plurais de afirmação de subjectividades e identidades em sociedades e regiões multiculturais» (Afonso, 2001: 20). Isto significa a necessidade de refundação de uma nova ordem da organização social do trabalho, potenciada por uma descomplexificação da sua divisão, que integre os saberes em circulação, não mais na linha da massificação informe, mas, em alternativa, na informação e direitos que permi-

1 Ver http://dre.pt/comum/html/legis/dudh.html 
tam ao sujeito reconstituir uma nova distinção correspondente à sua posição (Afonso, 2001).

Saindo ou nunca entrando no mercado de trabalho, mães há que, a despeito da sua alta formação académica, assumem a autogestão do seu autoemprego como estratégia de conseguirem um maior equilíbrio entre o ensino dos seus filhos e trabalho (quanto baste). Dado que esta atitude é uma alteração face aos padrões de carreira, passámos de seguida a conjugar fatores processuais e microculturais que influenciam os reconhecimentos materiais e simbólicos atribuídos pela mãe à profissão, assim como as relações de poder entre os profissionais de ambos os sexos que constituem a família em sentido estrito.

\section{Dos fatores contextuais ao contínuo laboral maternal}

A partir da possibilidade legal de praticar ensino doméstico em Portugal, mais de metade das famílias que o praticam vivem na região de Lisboa e Vale do Tejo, enquanto as restantes distribuem-se pelos distritos de Bragança, Vila Real, Braga, Porto, Aveiro, Coimbra, Castelo Branco, Leiria, Santarém, Évora, Faro, sabendo também que há casos de ensino doméstico nos Açores e na Madeira (Ribeiro, 2015). Nestes distritos, $54 \%$ das famílias vivem em zonas urbanas, $33 \%$ em zonas rurais e 13\% em zonas suburbanas (Ribeiro, 2015).

Do rendimento ilíquido anual destes agregados familiares, a grande diferença está na classe das famílias que auferem menos de 7.000 euros, em que as famílias sem religião quase que quadruplicam (17\%) face às famílias que professam uma religião cristã (5\%) (Ribeiro, 2015). Entre as restantes classes, as percentagens são aproximadas entre as que professam e as que não professam uma religião (Ribeiro, 2015). O facto de entre os dois grupos a maioria das famílias auferirem entre 20 mil e 40 mil euros anuais, parece consubstanciar um tipo de família-instituição e não família contrato (Ribeiro, 2015). Contudo, esta afirmação não deve ser entendida como uma generalização correlativa relevante na paisagem familiar contemporânea, pois há outros fatores que devem ser tomados em intersecção com elementos múltiplos.

Destas famílias, os diferentes modos de integração interna e externa decorrentes permitem-nos avançar com uma terminologia que apelida as famílias que praticam ensino doméstico em Portugal de saber tornar-se, saber estar com, saber ser e saber mudar (Ribeiro, 2015). As famílias saber ser encontram o seu paralelo na literatura internacional em pedagogues (Van Galen, 1991), earth-based (Stevens, 2001), open communion (Gaither, 2008) e natural choice (Morton, 2010). As famílias saber tornar-se nutrem grandes homologias nas famílias ideologues (Van Galen, 1991), heaven-based (Stevens, 2001), close communion (Gaither, 2008). Entre estes dois tipos de famílias, elencamos as famílias saber estar com que, apresentando algumas posições das famílias saber ser, não partilham absolutamente das suas características, tendo mesmo alguns traços comuns com as famílias saber tornar-se. 
Finalmente, as famílias saber mudar que respeitam os casos de alunos/as com necessidades educativas especiais. Todavia, ressaltamos que, se esta categorização nos permite traçar um raciocínio compreensivo da realidade portuguesa, terá as suas dificuldades em contemplar as sabidas e relatadas reconstruções estratégicas que vão sendo operadas ao longo do tempo, segundo tempos, espaços e contextos particulares (Kennedy, 2008).

Para as famílias saber tornar-se, do enfoque racional cristão a relação laboral com o ambiente externo é de intenção antinihilista, cujos esforços são feitos na linha da reforma narratívica da sociedade, procurando a sua recentração, reinterpretação e refundação segundo os valores cristãos. Conforme dizem,

Vemos um mundo restaurado de acordo com a intenção de seu Criador. ... uma cultura que sustenta o casamento de uma mulher com um homem ... confirma o casamento como o caminho para a saúde, segurança, realização e alegria... coloca o lar sobre a base do casamento como a origem da verdadeira soberania política, a fonte da democracia... família em que o lar, seu quintal e jardim estão cheios de atividade, com tarefas de utilidade com muitas crianças. Antevemos os pais como os primeiros educadores de seus filhos. Vemos lares que também abraçam os parentes de perto e de longe que precisam de cuidados especiais devido à idade ou enfermidade. Vemos vizinhanças, vilas e cidades como o segundo lugar de soberania política. Vemos uma liberdade de comércio que respeita e serve a integridade da família. E olhamos para os governos e nações que sustentam a proteção da família natural como sua responsabilidade prioritária (D6).

Para as famílias saber ser, conservadoras progressistas-libertárias, o enfoque humanista centra-se sobre o agente ativo do seu próprio processo de educação, socialização e profissionalização, segundo práticas centradas na comunicação, confiança incondicional e abertura à divergência, que se manifestam em comportamentos organizacionais sobre o ambiente informal de modo a favorecer o seu desenvolvimento e a autoaprendizagem, funcionando os adultos como assistentes. Partilhando com as famílias anteriores a flexibilização e a multigeracionalidade, a sua atitude laboral é de diversidade, sustentabilidade e indiferença sobre a soberania do homem comum:

E se nós não «educássemos"? Será que acabávamos por ser uma população mais educada? Imaginem o seguinte: um mundo onde nunca se fala sobre educação. Em vez disso, as pessoas simplesmente aprendem. Um mundo sem currículos, sem a ideia que todos nós 'temos que aprender' e 'temos que saber' determinadas coisas a determinada idade. Um mundo onde as pessoas têm a liberdade de desabrochar naturalmente, com muitos mais caminhos a tomar, muitas mais maneiras de ser. Será que seria muito diferente do nosso mundo atual? Será que as pessoas seriam mais felizes? Imaginem se andássemos preocupados com a possibilidade dos nossos filhos não conseguirem aprender a andar (B1). 
Entre estas duas tipologias, do enfoque simbioenergético de famílias saber estar com, a atitude laboral é de procura de uma coexistência funcional, abertura relacional, valorização da diferença, aceitação desinteressada, embora distanciando-se da exterioridade contrária, relativizando e reduzindo-a:

O ambiente escolar não é conducente a um processo de socialização saudável. Se fosse, as interações sociais no recreio seriam caracterizadas pela generosidade, humildade e respeito mútuo em vez da mesquinhez, agressividade e pressão do grupo típicas da interação social escolar. Os meus filhos brincam com os filhos dos nossos amigos. Não há bullying na nossa comunidade. A segregação etária imposta pela Escola não prepara os jovens para a interação entre adultos. Em vez disso, a expetativa das escolas é que as crianças suportem o tipo de comportamento hostil que nenhum adulto suportaria (B15).

Estes pluriposicionamentos das famílias decorrem das suas atitudes face aos ambientes que lhes são internos. As famílias saber tornar-se advogam uma atitude profissional transcendente correspondente às necessidades da família e da igreja. Essa satisfação deve ser em linha com a narrativa Bíblica dos cristãos.

Após uma série de estudos sobre a educação cristã, chegamos a conclusão da impossibilidade de manter os nossos filhos em escolas públicas. Não havendo nenhuma Escola particular guiada por princípios cristãos em nossa região, resolvemos trabalhar em conjunto para que os nossos filhos tivessem uma educação baseada em princípios bíblicos e que ao mesmo tempo fosse de qualidade. No início, e ainda hoje, encontramos muitas dificuldades, como em relação ao material, a metodologia, as perseguições e etc. (E14)

Neste sentido, num contínuo analítico entre a interioridade e a exterioridade, prevalecem os conceitos de estatuto, obediência e ordem a fim de que $o$ implícito seja interiorizado através de uma atividade de díade primária.

As famílias saber ser situam-se num extremo atitudinal profissional assente no primado da autonomia, interesse e paixão do indivíduo. Por isso adotam uma atitude não diretiva e ecológica que seja significativa ao indivíduo que é autocentrado e observacional: os seus sinais são compreendidos pelos pais através da profunda confiança e empatia em que a família se desenvolve. A criança vive no seio familiar, juntinho aos pais, sem medo de ser abandonada na Escola, dia e noite em conexão. Como sublinha Agnes Sedlmayr, a criança cresce e desenvolve-se ao seu próprio ritmo, na comunidade da sua família e do grupo em que estão inseridos jovens, adultos, idosos, que a conhecem e com as quais tem ligações afetivas (2014: 12).

As famílias saber estar com desenvolvem o primado da relação profissional assente na partilha e reciprocidade, posicionando-se em favor da negociação estratégica, parceria e mediação assente em dinâmicas profissionais de díade conjunta. 
A aprendizagem é muitas vezes incidental. Isto significa que nós aprendemos quando estamos completamente envolvidos em atividades que gostamos, que fazemos por prazer, e que a aprendizagem acontece como uma espécie de «efeito secundário. A aprendizagem é muitas vezes uma atividade social e não algo que acontece em isolação dos outros. Aprendemos com pessoas que têm as competências e conhecimentos em que estamos interessados e que nos deixam aprender com elas numa variedade de maneiras. Não precisamos de fazer testes nem de ser avaliados para sabermos o que é que já aprendemos. A aprendizagem será demonstrada ao usarmos as nossas novas habilidades e ao falarmos com conhecimento sobre determinados tópicos. Os sentimentos e o intelecto não estão em oposição nem estão separados. Toda aprendizagem envolve tanto as emoções como o intelecto (B1).

Daqui, destas tipologias, decorre um contínuo concetual entre dois tipos de schemata das mães face dever laboral doméstico.

\section{Da schemata crente cristã conservadora protestante}

A schemata crente cristã conservadora protestante assume uma orientação organizacional laboral mais propensa a estipular como é que as coisas devem ser feitas, segundo os conceitos de direção, hierarquias, orientação e treino, relações apropriadas de autoridade, condenação do uso de punições corporais e de meios físicos para a disciplina (Ribeiro, 2015). A algumas pessoas é-lhes reconhecida mais autoridade do que a outros e os múltiplos interesses individuais são legitimamente subssumidos em função das necessidades e interesses coletivos (Pride, 1985). Se os filhos são considerados como os educandos e formandos e o pai/marido como o Chief Effectiveness Officer, a mãe/esposa é a grande administradora do plano (plan manager) (Pride, 1985). A leitura hierárquica é feita de forma implícita e explícita: implícita quando se trata de dizer como é que os filhos devem ser tratados, como é que as esposas se devem relacionar com os seus maridos e como é que estes devem ser sensíveis à vontade Divina; explícita quando consideram a autoridade que Deus tem sobre a família.

Lendo estas relações segundo os fundamentos da organização burocrática (Weber, 1978), a efetividade da autoridade legal do protestantismo conservador repousa em aceitações interdependentes de que toda a norma legal laboral pode ser estabelecida por acordo e também por imposição quando as famílias percebem a sua ligação aos fins e valores racionais. A norma laboral estabelecida será obedecida pelos membros da família mesmo quando as pessoas não estão dentro da esfera do poder. Este processo administrativo dos interesses racional é sempre dentro dos limites estabelecidos pelos preceitos legais.

A mãe, mulher, vive uma subordinação laboral consciente a uma ordem pessoal no sentido de uma obediência racionalmente delimitada de autoridade segundo os termos de ordem que lhe foi conferida. Portanto, a mãe de família é a 
gestora familiar de uma organização contínua de cargos delimitados por normas da igreja dentro de áreas específicas de competência, com obrigações de desempenho de funções diferenciadas como parte de uma sistemática divisão do trabalho. Esta relação de submissão decorre do primado transcendental no qual a mãe crente parte do pressuposto que foi o cristianismo que a incumbiu dessa tarefa, da mesma forma que escolheu o seu marido e os filhos. A mãe é colocada no centro da ação recebendo muitas vezes um reconhecimento social mais visível (Stevens, 2001; Kunzman, 2009; Ribeiro, 2015). A postura dos crentes cristãos conservadores protestantes sobre a mulher e mãe é que abandonem o ideal liberal feminista e voltem a viver aquilo que lhes é a vontade Divina sobre os trabalhos domésticos (Stevens, 2001; Ribeiro, 2015). As conquistas feministas são opressivas e liberalizadoras pois desenvolvem uma mente anticristã. No que diz respeito à figura masculina do casal, a ideia que recolhemos é que todos os pais devem exercer uma liderança espiritual real nas suas famílias, educar a criança através da disciplina, ao mesmo tempo que é estimulado a ser um pai benevolente e o primeiro responsável pelo income familiar (Stevens, 2001; Ribeiro, 2015).

Em teoria, os protestantes conservadores pregam assiduamente a submissão feminina e maternal, mas na prática as esposas são as 'rainhas do lar' e têm uma voz muito ativa nas decisões da igreja (Klicka, 2002). Elas são as peritas locais que sabem todos os detalhes do projeto familiar, que é coletivo, e assumem a responsabilidade diária do lar (Stevens, 2001). São também muito ativas na promoção e manutenção de grupos de apoio locais e regionais (Stevens, 2001; Ribeiro, 2015). Mesmo que este compromisso coletivo de criar um lar educativo cristão seja intelectualmente coerente e decididamente hostil para algumas prerrogativas do feminismo liberal, para estas mães, a sua opção parece não se fazer por completa negação aos projetos de vida anteriores. Ao afirmarem que a sua dedicação à tarefa laboral doméstica se faz por referência a um ideário religioso, é uma ação intencional, sistemática e contextualizada para normalizar um papel e estatuto que todas as mães crentes cristãs deveriam aspirar (Klicka, 2002; Farris, 2013).

\section{Da schemata conservadora progressista-libertária}

Contrariamente em vários aspetos à mãe crente cristã, a schemata progressista-libertária, a mãe assume um compromisso invisível. No tipo ideal, as suas funções educativas são a assistência ao progresso da criança, responder, perguntar e assegurar que a criança respeita as exigências pediátricas: a mãe tende a desaparecer ao longo das exposições do potencial das crianças, praticando uma atitude passiva, não se envolvendo diretamente, pretendendo somente facilitar a aprendizagem (Ribeiro, 2015). Sendo a agenda determinada pela criança, a mãe poderá sugerir e a criança tem a liberdade de recusar. Está sempre presente, mas para providenciar os recursos necessários para a aprendizagem e criar um ambiente que nutra as necessidades da criança; o pai situa-se na periferia domés- 
tica (Ribeiro, 2015). A mãe é a coordenadora semiperiférica de quotidianos diferentes em vários lugares de aprendizagem (cidade, cinema, aeroportos, floresta, museus, praia, rua, supermercado, teatro, viagens, visitas de estudo, oficinas, parques, piscina, companhia de dança, espaços associativos, espaços públicos, estações, galeria de arte, livrarias, transportes públicos, ludotecas, portos, restaurantes) (Ribeiro, 2015).

Nos grupos focais, diante do mesmo objeto natural, a mãe intuitiva deixa-se observar e escutar num meio circular que regista as horizontalidades na diversidade, que recolhe os fragmentos da descontinuidade, da irregularidade, de escalas diferentes (Ribeiro, 2015). Paralelamente à schemata anterior, sendo mãe presente é uma mãe de pressentimentos, de sensibilidades interiores ao self.

Dado que esta mãe é a dos biorritmos de cada um: «Nós levantamo-nos quando acabamos de dormir e deitamo-nos quando temos sono. Tem todo o sentido e faz-nos pensar nos horários para tudo que raras vezes são consonantes com o nosso biorritmo» (FG5), encontramos neste modelo organizacional, na linguagem de Karl Weick (1976), uma indeterminabilidade causal (incerteza a ambiguidade) laboral. Uma outra causa da débil articulação é a fragmentação do meio externo dado os estímulos dispersos e a ausência de expetativas (Orton e Weick, 1990).

Ao assumirem o contrário de «cumprimento de obrigações, disciplina e mais disciplina, regras para tudo, horários para tudo, espartilhos por todo o lado» uma vez que sentem «que todo esse apertado espartilho não nos levou a lado nenhum, muito pelo contrário, a mãe abraça a maneira como se quer sentir «feliz, conectada aventureira» (FG5). Para isto focalizam-se em que «a confiança, liberdade e compaixão sejam os [seus] guias» (FG5). Nesta focalização a mãe diz agir por respeito e tolerância tentando aceitar os seus filhos e filhas como são, proporcionando-lhes as ferramentas necessárias para o seu desenvolvimento físico e emocional na direção que desejam (Sedlmayr, 2014).

Neste processo de aceitação não valorizam a obediência ou regras, pois «as regras na nossa vida não existem separadas da própria vida, não há limites impostos pelos adultos» (Sedlmayr, 2014: 56). Esta ausência geral de regras no labor diário fragmenta a participação, articulando debilmente tais singularidades com as expetativas sociais, mais racionais e burocráticas. Prova disso é que, na terminologia de Tony Bush (1986; 1994), a gestão maternal da determinação dos objetivos é democrático, a sua definição é subjetiva quando se procura o desenvolvimento dos valores e símbolos compartilhados, e democrática/colegial quando se envolvem as pessoas num clima de abertura. Também o processo de determinação dos objetivos é democrático, pois assenta no consenso emergido da base familiar num processo participativo. Por isso, a relação entre objetivos e decisões é democrático como um processo de abertura para assumir compromissos. A natureza da estrutura organizacional segue na via de recursos humanos quando se aduz em apoio de momentos informais de partilha de sentimentos, fortalecimento do compromisso e empenhamento destas famílias. Segue-se no 
sentido de um certo simbolismo e subjetivismo de Lee Bolman e Terrence Deal (1984), quando se pretendem ocasiões para celebrar e transformar as subculturas e mesmo traços contraculturais que possam partilhar. Para alcançar os seus objetivos, a mãe unschooler tece uma estrutura organizacional doméstica que seja futurista no fulcro, isto é, na consciência, vontade, valores do ser, saber, fazer. Os conflitos parecem ser tratados da forma simbólica de Bolman e Deal (1984), através do processo basilar de comunicação onde os intervenientes procuraram desenvolver valores compartidos e usar o conflito existente para a negociação de significados em função dos objetivos narratívicos.

Entre a mãe crente cristã protestante e a mãe ambígua, está a mãe simbioenergética. Com Bolman e Deal (1984), na planificação, tratamento de conflitos, comunicação e reuniões, as famílias simbioenergéticas conjugam os seus comportamentos entre as perspetivas dos recursos humanos e os simbolismos: promoção da participação, dar confiança, desenvolver relações interpessoais e valores compartidos, negociar significados, trocar sentimentos e contar histórias, partilhar sentimentos para celebrar e transformar a cultura. Com Bolman e Deal (1984), a motivação para o crescimento e para a realização pessoal é feita segundo a manutenção de uma relação entre as necessidades humanas e os papéis formais, o processo de determinação dos objetivos e as relações entre objetivos e decisões assentam em perspetivas democráticas baseadas em objetivos de consenso que se repercutem na natureza do processo de decisão colegial. A natureza da estrutura é objetiva, mas as suas possibilidades lateralizantes atribuem-lhe alguma subjetividade ao nível do produto da interação entre os indivíduos.

Esta visão interacionista relaciona-se com o ambiente sob a forma de diluída responsabilidade pela partilha da decisão. Entre a estrutura e a ambiguidade, a tomada de decisão assume crescente abertura para assumir compromissos, definindo-os de forma a manter as pessoas envolvidas num clima de abertura (Bush, 1986; 1994). O modo de coesão, ao assentar no primado da relação, evoca os princípios da partilha, reciprocidade e mútuo respeito. As famílias referem que desenvolvem relações valorizando a diferença, regulando-se através de estratégias de negociação, decisão, parceria e diálogo (Ribeiro, 2015).

Entre estas schematas estamos perante micro-organizações familiares, tipo construtos e produtos humanos, cuja cultura e identidade são a capacidade própria de aprendizagem. Baseando-se no conhecimento, as famílias referem que o seu sucesso consistirá na capacidade de gerirem relações entre mãe e filho e em estimular e gerir o conhecimento e a aprendizagem organizacional. Numa relação de interdependência, reciprocidade e conjunto, os pais e os filhos verificam, analisam e sintetizam factos e informações através de processos de decisão partilhados. Em relações de proximidade genuínas, exibem valores de parceria, não numa hierarquia de dominação, mas numa hierarquia de realização onde a estrutura de gestão promove a realização do potencial de cada pessoa. Sem ser um tipo de organização familiar de knowledge specialists, as micro-organizações familiares aproximam-se mais de uma information-based organization que motiva as 
mães a uma perspetiva de aprendizagem baseada em relacionamentos estimuladores do desenvolvimento das potencialidades individuais, tornando o educando num indivíduo capaz e com gosto por aprender.

Numa relação de conjunto, procura-se incrementar o processo de aprendizagem através da ação e da reflexão desde a base. Cede-se informação, estabelece-se comunicação, deixa-se agir, estimula-se a ação por parte de todos aqueles que pertencem à organização - pensar e agir fazem parte das competências e das responsabilidades, dando-se-lhe tempo para isso. Apologistas da democratização da informação e da comunicação, as mães funcionam estavelmente num ambiente de mudanças tecnológicas constantes e radicais, dado que têm a capacidade de alterar a natureza do trabalho com criatividade, inovar e aprender por transformação e mudança.

A facilidade de adaptação à mudança é decorrente das práticas de ensino doméstico que desenvolvem quotidianamente. As mães encorajam a colocação de questões, emitem feedback direto e individual quanto ao desempenho, permitem a realização de tarefas e a constituição de grupos adhocráticos em função do tema em estudo, encorajam a partilha do processo de decisão, motivam para mudar, variam a sua atuação em função dos aspetos pessoais e fortalecem o coletivo familiar através de uma política de comunicação em todos os níveis extensivos da família.

Mais no sentido progressista-libertário estamos diante de micro-organizações nas quais as mães aprendem organizacionalmente e facilitam a aprendizagem, preparando-se para lidar com o processo de mudança que caracteriza a sociedade atual.

Ora, posto isto, se até agora procuramos dar exame do ensino doméstico em Portugal como um novo movimento social que provê contexto organizacional para a renovação do estatuto e papel laboral e profissional da mãe que deixa a sua carreira, ou opta por nunca nela entrar, para se dedicar à educação dos seus filhos, é necessário agora concluirmos sobre o tipo de trabalho que é requerido à mãe no ensino doméstico e o que subjaz e permeia a produção de soluções de mercado e de trabalho para satisfazerem os seus interesses e necessidades ideológicas.

\section{Conclusões}

No sentido crente cristão conservador protestante, a crescente feminização da administração do ensino doméstico em Portugal não só contraria a crescente feminização da profissão, como as alterações verificadas no reconhecimento material e simbólico atribuído à profissão, assim como nas relações de poder entre os profissionais de ambos os sexos, contrariam também a discursividade social de desigualdades de género permanentes. Neste sentido analítico, recorrendo a Max Weber (1990: 118), o que acontece é que diante de um «desencantamento radical do mundo ao nível da interioridade», a mãe assume o legado cris- 
tão de se especializar na inserção dos valores da sua narrativa, dando não só um outro sentido ao que deverá ser a profissão da mulher mãe, como outras motivações para a intensificação do interesse económico da profissão dos protestantes.

Desta relação, o enorme significado que a doutrina protestante confere ao controlo da consciência humana enquanto revelação individual de Deus, imprime um novo carácter ao estatuto e papel da mulher no mundo das profissões. Se os cargos públicos não são desejados pois são instituintes, a afeição pela propriedade privada é a prioridade dado que propicia a livre expressão da consciência cristã. A mãe é a gestora de micro-organizações de percursos familiares racionais, «orientada pela vontade de Deus» (Weber, 1990: 120).

Agora em ambos os sentidos, sendo a mãe a plan manager de percursos familiares de um projeto coletivo, a procura de especialização em tudo aquilo que for necessário para o desempenho da sua função faz dela um agente de mudança de pluridestrezas para assegurar o common best da sua família e das linhas sociais em que se move. Daqui, sob a inspiração de Weber (1990), no limite, estaremos diante de mulheres que se vão qualificando superiormente ao longo do tempo segundo os interesses e necessidades do plano. Isto em contraponto crítico a uma atitude uniprofissional (unfaithful) que, segundo as mães, é a mulher habilitada superiormente.

Nesta carreira familiar sem fronteiras, a mãe constitui um novo modelo que abandona definitivamente a ideia de carreira delimitada por fronteiras organizacionais e abraça o conceito de autogestão da sua vida e gestão da sua família. Nesta lógica, não há uma separação ideológica entre as esferas de ação do parentesco e da economia. O que há é conjugação entre a família e suas relações interpessoais, com a produção das atividades económicas e relações sociais, através das quais se produz e reproduz o sistema social.

Daqui se diz que, e contrariamente a algumas formas de pensar a administração da organização, a família em sentido restrito que decorre da interseção entre a família em sentido amplo e o grupo doméstico, é crucial ao nível das relações sociais e dos sentimentos de parentesco para a produção e reprodução do desempenho económico das micro-organizações familiares enquanto microgrupos empresariais que podem vir a ocupar um lugar de destaque na economia nacional. É nesta relação entre a identidade familiar e o prestígio empresarial que as mulheres conseguem um maior equilíbrio entre a vida doméstica (prioridade) e o trabalho. É nestes crescentes microuniversos de parentesco e empresa familiar que se criam as condições para a manutenção de relações familiares ativas ao longo do tempo. E, inversamente ao pensamento empresarial comum, a riqueza e o prestígio social são acessórias e não principais fontes de permanência e continuidade das relações familiares.

Uma outra nota digna de registo é que as famílias que praticam ensino doméstico, sendo micro-organizações, afastam-se do estereótipo social de fluidez e informalidade, para se afirmarem, mais num sentido do que noutro, como estruturadas com uma existência física, espacial e temporal, com objetivos especí- 
ficos, organigrama e funções levadas a cabo por sujeitos que se formam continuamente dentro de uma densa rede de relações, sentimentos e projetos familiares que unem os membros da família como acionistas na construção de relações empreendedorismo familiar.

A unidade familiar é um ideal que visa assegurar a solidariedade entre os seus membros para sustentar a continuidade dos negócios educativos e empresariais familiares. Crescendo imersos neste sentimento familiar, a finalidade parental é que os educandos incorporem este espírito empreendedor e o desejo de assegurar a continuidade. Contudo, e para finalizar, é importante estudar, ao longo do tempo, o processamento das transições que a mãe enfrenta depois do fim da escolaridade obrigatória dos seus filhos. Existe mobilidade analítica de volta ao mercado das profissões? Que estratégias de mobilidade estão a ser utilizadas?

\section{Referências bibliográficas}

Afonso, Almerindo (1998), Políticas educativas e avaliação educacional. Para uma análise sociológica da reforma educativa em Portugal (1985-1995), Instituto de Educação e Psicologia, Universidade do Minho, Braga.

Afonso, Almerindo (2001), "Os lugares da educação», in Olga Simson, Margareth Park e Renata Fernandes (org.), Educação não-formal. Cenários da criação, Campinas, Editora da Unicamp/Centro de Memória, 29-38.

Apple, Michael (2001), Educando à direita. Mercados, padrões, Deus e desigualdade, São Paulo, Cortez Editora.

Apple, Michael (2012), «Doing the work of God: home schooling and gendered labor», in Michael Apple, Stephen Ball e Luís Gandin (eds.), The Routledge International Handbook of the Sociology of Education, Routledge Taylor \& Francis Group, London and New York, 145-154.

Arthur, Michael (1994), «The boundaryless career: A new perspective for organizational inquiry", Journal of Organizational Behavior 15, 295-306.

Bendell, Jean (1994), "Parents who choose to educate their children at home», in Mark Halstead (ed.), Parental choice and education. Principles, policy and practice, London. Kogan Page, 151-163.

Bolman, Lee; Deal, Terrence (1984), Modern approaches to understanding and managing organizations, San Francisco, Jossey-Bass.

Bourdieu, Pierre (1984), Distinction: A social critique of the judgement of taste, Harvard, Routledge \& Kegan Paul, Ltd.

Bourdieu, Pierre (1990), Coisas ditas, São Paulo, Brasiliense.

Bourdieu, Pierre (2005), Sobre a televisão, Oeiras, Celta Editora.

Bush, Tony (1986), Theories of educational management, London, Harper \& Row.

Bush, Tony (1994), «Theory and practice in educational management», in Tony Bush \& West-Burnham (eds.), The principles of educational management, London, Longman, 33-53 .

Dubet, François (2003), «A Escola e a exclusão», Cadernos de Pesquisa 119, 29-45.

Estêvão, Carlos (1998), Redescobrir a escola privada portuguesa como organização, Instituto de Educação e Psicologia - Universidade do Minho, Braga.

Farris, Michael (2013), «Tolerance and liberty: answering the academic left's challenge to 
homeschooling freedom», Peabody Journal of Education 88, 393-406, disponível em http://www.tandfonline.com/doi/pdf/10.1080/0161956X.2013.798520, consultado em 10 de dezembro de 2014.

Freitas, Sandra (2015), «Quadriplicam pais que dão aulas em casa», Jornal de Notícias (1 de fevereiro).

Gaither, Michael (2008), Homeschool: An American history, New York, Palgrave Macmillan.

Kennedy, Earl (2008), Homeschooling as reflexive modernity, disponível em http://repository. lib.ncsu.edu/ir/bitstream/1840.16/1355/1/etd.pdf, consultado em junho 25 de junho de 2013.

Klicka, Christopher (2002), The heart of homeschooling. Teaching \& living what really matters, Nashville, Tennessee, Broadman \& Holman Publishers.

Kunzman, Robert (2009), Write these laws on your children. Inside the world of conservative christian homeschooling, Boston, Beacon Press.

Landis, Richard; Koch, Gary (1977), «The measurement of observer agreement for categorical data», Biometrics 33, 159-174.

Maruyama, Geoffrey; Deno, Stanley (1992), Research in educational settings, London, Sage.

Morton, Ruth (2010), «Home education: constructions of choice», International Electronic Journal of Elementary Education 3(1), 45-56.

Orton, Douglas; Weick, Karl (1990), «Loosely coupled systems, a reconceptualization», Academy of Management 15(2), 203-223.

Pride, Mary (1985), The way home, Missouri, Home Life Books.

Ribeiro, Álvaro (2010), O ensino doméstico e a organização escolar: um contributo sociológicoorganizacional sobre a realidade portuguesa, Dissertação de Mestrado, Universidade do Minho, Braga, Portugal.

Ribeiro, Álvaro (2015), O ensino doméstico em Portugal: uma abordagem sobre novas epistemologias organizacionais da educação, das subjetividades e dos quotidianos familiares, Tese de Doutoramento, Universidade do Minho, Braga, Portugal.

Santos, Boaventura (2001), «Os processos da globalização», in Boaventura Sousa Santos (ed.), Globalização - fatalidade ou utopia?, Porto, Edições Afrontamento, 31-105.

Sedlmayr, Agnes (2014), Livre para crescer - sustentabilidade emocional, parentalidade com apego e unschooling (e-book), Smashwords, Inc. (https://www.smashwords.com/).

Stevens, Mitchell (2001), Kingdom of children. Culture and controversy in the homeschooling movement, Oxford, Princeton University Press.

Van Galen, Jane (1991), «Ideologues and pedagogues: parents who teach their children at home», in Van Galen e Mary A. Pitman (eds.), Home schooling - political, historical and pedagogical perspectives, Norwood, New Jersey, Ablex Publishing Corporation, 63-76.

Weber, Max (1978), «Os fundamentos da organização burocrática: uma construção do tipo ideal», in Edmundo Campos (ed.), Sociologia da burocracia, Brasil, Rio de Janeiro, Zahar Editores, 5-28.

Weber, Max (1990), A ética protestante e o espírito do capitalismo, Lisboa, Editorial Presença.

Weick, Karl (1976), «Educational organizations as loosely coupled systems», Administrative Science Quarterly 21(1), 1-19.

\section{Outras referências}

FG5, D6, B15, E14 são codificações de documentos analisados. 
Álvaro Ribeiro. Professor no Departamento de Ciências Sociais do Instituto de Educação da Universidade do Minho; Membro da equipa de investigação do projeto Excel.pt - Between More and Better School: academic excellence in Portuguese State schools. Project reference - PTDC/IVC-PEC/4942/2012; Aguarda defesa de provas de doutoramento da tese intitulada «O ensino doméstico em Portugal: uma abordagem sobre novas epistemologias organizacionais da educação, das subjetividades e dos quotidianos familiares».

Endereço: Álvaro Ribeiro, Rua do Progresso, n.. 57, bloco A1, habitação 13. 4410-032, Serzedo, Vila Nova de Gaia. Portugal. alvarochaves.ribeiro@gmail.com

Artigo recebido em 16 de novembro de 2015 e aceite para publicação em 27 de abril de 2016. 